\title{
Janzen-Connell effects in a broadcast-spawning Caribbean coral: distance-dependent survival of larvae and settlers
}

\author{
K. L. Marhaver,,${ }^{1,2,5}$ M. J. A. Vermeij, ${ }^{2,3}$ F. Rohwer, ${ }^{4}$ and S. A. Sandin ${ }^{1}$ \\ ${ }^{1}$ Center for Marine Biodiversity and Conservation, Scripps Institution of Oceanography, University of California-San Diego, \\ La Jolla, California 92093 USA \\ ${ }^{2}$ CARMABI Foundation, Piscaderabaai z/n, Willemstad, Curaçao \\ ${ }^{3}$ Aquatic Microbiology/Institute for Biodiversity and Ecosystem Dynamics, University of Amsterdam, Amsterdam, The Netherlands \\ ${ }^{4}$ Department of Biology, San Diego State University, San Diego, California 92182 USA
}

\begin{abstract}
The Janzen-Connell hypothesis states that host-specific biotic enemies (pathogens and predators) promote the coexistence of tree species in tropical forests by causing distance- or density-dependent mortality of seeds and seedlings. Although coral reefs are the aquatic analogues of tropical forests, the Janzen-Connell model has never been proposed as an explanation for high diversity in these ecosystems. We tested the central predictions of the Janzen-Connell model in a coral reef, using swimming larvae and settled polyps of the common Caribbean coral Montastraea faveolata. In a field experiment to test for distance- or density-dependent mortality, coral settler mortality was higher and more strongly density dependent in locations down-current from adult corals. Survival did not increase monotonically with distance, however, revealing the influence of fluid dynamics around adult corals in structuring spatial patterns of mortality. Complementary microbial profiles around adult coral heads revealed that one potential cause of settler mortality, marine microbial communities, are structured at the same spatial scale. In a field experiment to test whether factors causing juvenile mortality are host specific, settler mortality was 2.3-3.0 times higher near conspecific adults vs. near adult corals of other genera or in open reef areas. In four laboratory experiments to test for distance-dependent, host-specific mortality, swimming coral larvae were exposed to water collected near conspecific adult corals, near other coral genera, and in open areas of the reef. Microbial abundance in these water samples was manipulated with filters and antibiotics to test whether the cause of mortality was biotic (i.e., microbial). Juvenile survivorship was lowest in unfiltered water collected near conspecifics, and survivorship increased when this water was filter sterilized, collected farther away, or collected near other adult coral genera. Together these results demonstrate for the first time that the diversity-promoting mechanisms embodied in the Janzen-Connell model can operate in a marine ecosystem and in an animal. The distribution of adult corals across a reef will thus influence the spatial pattern of juvenile survival. When rare coral species have a survival advantage, coral species diversity per se becomes increasingly important for the persistence and recovery of coral cover on tropical reefs.
\end{abstract}

Key words: coral; density dependence; distance dependence; diversity; Janzen-Connell hypothesis; larvae; marine invertebrates; microbes; Montastraea faveolata.

\section{INTRODUCTION}

Ecologists have long sought to explain why groups such as trees, corals, plankton, and bacteria have remarkably high species diversity given that they occupy seemingly homogeneous habitats (Hutchinson 1961, Connell 1978, Dykhuizen 1998). To explain the maintenance and generation of diversity in tropical tree communities, Janzen (1970) and Connell (1971) pro-

Manuscript received 13 June 2012; accepted 9 July 2012; final version received 15 August 2012. Corresponding Editor: R. B. Aronson.

${ }^{5}$ Present addresses: CARMABI Foundation, Piscaderabaai z/n, P.O. Box 2090, Willemstad, Curaçao; University of California, 5200 North Lake Road, Merced, California 95343 USA. E-mail: kmarhaver@ucmerced.edu posed theories that together became known as the Janzen-Connell hypothesis: tree seeds and seedlings are less likely to survive in close proximity to conspecific adults because each adult tree attracts and harbors a suite of species-specific herbivores, seed predators, and plant pathogens. Due to the species-specific nature of this mechanism, Janzen-Connell effects promote the survival of rarer species and help maintain high tree diversity overall. Despite difficulties inherent in studying slow-growing species with myriad potential pathogens and predators, the body of literature supporting the Janzen-Connell hypothesis includes experimental evidence that species-specific plant pathogens cause distance-dependent mortality of both seeds and seedlings (Augspurger 1983, Gilbert et al. 1994, Packer and Clay 2000, Bell et al. 2006). Forty years after its emergence, 
the Janzen-Connell hypothesis continues to provide a popular and useful framework for examining the forces contributing to terrestrial plant diversity.

In contrast to terrestrial ecological theory, the forces creating and maintaining coral reef diversity have typically been considered separately by marine ecologists, with a heavier focus on abiotic and non-ecological mechanisms. Coral speciation is generally attributed to abiotic factors such as light, temperature, currents, and storm damage (Connell 1978, Veron 1995) and nonecological factors such as polyploidization (Kenyon 1997; but see Carlon et al. 2002 for evidence of ecological speciation in a coral). Species coexistence on the other hand has been explained by ecological factors in a small number of studies. For example, the coexistence of corals and other encrusting invertebrates may be maintained by competitive dominance networks mediated by allelopathy or physical aggression (Lang 1973, Jackson and Buss 1975, Buss and Jackson 1979). Similarly, predation can promote coral species coexistence if predators favor abundant species and thereby prevent competitive dominance (Paine 1969, Porter 1972).

Importantly, the high phenotypic plasticity and morphological convergence of reef corals has longobscured their true species boundaries and phylogenetic relationships. Studies of reproductive behavior (Van Moorsel 1983, Levitan et al. 2004), skeletal microstructure (Fukami et al. 2004), aggressive interactions (Knowlton et al. 1992), demographic parameters (Vermeij and Bak 2003), microhabitat use (Vermeij et al. 2007), and molecular genetics (Fukami et al. 2004) have greatly improved coral taxonomy, revealing that corals are more speciose and their niches are more narrow than previously thought. Knowlton and Jackson (1994) argued that blurred species boundaries have traditionally prevented scientists from accurately identifying the habitat specializations of coral species. Thus, Connell himself concluded that niche diversification could not maintain coral species diversity due to their broad species ranges and a lack of habitat specialization (1978). Instead, he argued that physical disturbance was responsible for maintaining species diversity in coral assemblages by preventing communities from achieving an equilibrium state.

Despite the differences in the theoretical treatment they have been given by ecologists, corals are the marine analogs of rain forest trees because they create threedimensional habitats for thousands of other organisms, use photosynthesis to produce energy, compete with each other for space, and disperse as juveniles but live their adult lives in a fixed location. Given these similarities, Janzen proposed that his model of distance-dependent mortality for tree seedlings should also apply to long-lived sessile marine invertebrates that compete for space and suffer high mortality as juveniles (Janzen 1970). Janzen, however, did not mention corals, focusing instead on rocky intertidal organisms.
In sum, the idea that Janzen-Connell effects occur in scleractinian reef corals has never been tested experimentally. Notably, because the Janzen-Connell hypothesis invokes the spatially explicit action of host-specific enemies over a timescale of many generations of the host, corals are one of very few animal groups that are suitable organisms for such an experiment. Observational evidence from one coral species showed that juveniles suffer decreased survivorship and recruitment as the local cover of conspecific adults increases; this effect occurred before all available space (and light) was occupied, suggesting that the mortality of coral juveniles was caused by a waterborne factor whose effect became stronger as coral cover increased (Vermeij 2005, Vermeij and Sandin 2008).

Coral-associated microbial communities are highly diverse, generally host specific at the genus level, and generally stable over space and time (e.g., Rohwer et al. 2002, Koren and Rosenberg 2006, Rosenberg et al. 2007). These communities include ubiquitous potential pathogens (Kline et al. 2006, Wegley et al. 2007), which are controlled by the coral's mucus chemistry (Brown and Bythell 2005, Ritchie 2006), coral-associated bacteriophage (Marhaver et al. 2008, Efrony et al. 2009), and other bacteria in the holobiont (Reshef et al. 2006, Ritchie 2006, Rypien et al. 2010). Changes in the microbial community due to potential pathogens residing on the host, outside pathogens, or general microbial community dysfunction may cause morbidity and mortality (Kline et al. 2006, Harvell et al. 2007, Rohwer and Youle 2010). Juvenile corals are particularly susceptible to microbial attack (Vermeij et al. 2009) due to their small size, immature immune systems (Frank et al. 1997), and lack of a fully developed protective microbial consortium (Apprill et al. 2009, Sharp et al. 2010). Coral-associated microbes are therefore potential candidates to serve as the speciesspecific biotic "enemies" faced by young coral settlers in the reef environment.

Using juveniles of the Caribbean coral Montastraea faveolata, we sought to test three predictions of the Janzen-Connell hypothesis: that juvenile mortality is distance or density dependent, that juvenile mortality near adults is taxon-specific, and that this mortality is caused by host-specific biotic enemies. This represents the first explicit test of the Janzen-Connell hypothesis in an ocean ecosystem and in an animal group.

\section{Materials And Methods}

\section{Study system}

Montastraea faveolata (mountainous star coral) is a massive, boulder-forming coral that dominates shallow Caribbean reefs. For this study, M. faveolata planula larvae (planulae) were reared from gametes collected during five mass spawning events on the island of Curaçao in the southern Caribbean. Gametes were collected by placing weighted nylon cones over spawning corals at 7-9 $\mathrm{m}$ depth at Snake Bay (September 
2007 and October 2008; $12^{\circ} 08^{\prime} 20^{\prime \prime} \mathrm{N}, 68^{\circ} 59^{\prime} 52^{\prime \prime} \mathrm{W}$ ), Playa Kalki (September 2008 and September 2009; $12^{\circ} 22^{\prime} 29^{\prime \prime} \mathrm{N}, 69^{\circ} 09^{\prime} 30^{\prime \prime} \mathrm{W}$ ), and the Water Factory (October 2009; 12 $06^{\prime} 33^{\prime \prime} \mathrm{N}, 68^{\circ} 57^{\prime} 16^{\prime \prime} \mathrm{W}$ ). Embryos were raised to the swimming planula stage using methods developed previously for mass spawning coral species (Vermeij et al. 2006, 2009). Because M. faveolata planulae can disperse for weeks to months in the plankton, juveniles of this species are highly unlikely to settle near a parent colony. Thus all field experiments, microbe counts, and water collections for laboratory experiments were conducted using a group of nonparent coral colonies located on a reef flat directly to the south of Carmabi Buoy Zero $\left(12^{\circ} 12^{\prime} 35^{\prime \prime} \mathrm{N}, 68^{\circ} 97^{\prime} 10^{\prime \prime} \mathrm{W}\right)$ at depths of 5-6 m. The prevailing water current at this site is extremely consistent in direction and strength because it is driven by the easterly trade winds (Van Duyl 1985).

\section{Field experiments}

Laboratory-reared $M$. faveolata planulae were allowed to settle and metamorphose onto clean glass microscope slides (Fig. 1A). The location of settlers on each slide was mapped before slides were deployed to the field. Slides were secured underwater to small limestone tiles $(2 \times 4 \mathrm{~cm})$ with plastic tie-wraps (Fig. 1B). Tiles were held to PVC scaffolds using a plastic expansion plug. Tie-wraps touched only the edges of the microscope slides and the limestone tile, but not the surface of the microscope slide holding the settled polyps.

Distance-dependence experiment.-PVC spokes $(2 \mathrm{~m}$ long, situated $15 \mathrm{~cm}$ above the reef benthos) were installed extending up-current $(n=7)$ and down-current $(n=8)$ from eight adult $M$. faveolata coral colonies in an open sand flat (Fig. 1C). A total of 445 settlers on 105 slides were deployed; slides were secured horizontally at distances of $3,6,12,24,48,96$, and $192 \mathrm{~cm}$ in each direction. The survivorship of each settler was scored daily for six days.

Species-specificity experiment.-PVC tees $(12 \mathrm{~cm}$ long PVC arms placed $15 \mathrm{~cm}$ above the benthos) were installed next to boulder-shaped coral colonies of three different genera ( $n=5$ per treatment) to hold coral settlers vertically within $2 \mathrm{~cm}$ of the surface of the adult coral (Fig. 1D). In order to test the hypothesis that taxon-specific mortality is caused by a waterborne factor, all settlers were placed beyond the reach of each adult coral's tentacles. Tees were placed such that the PVC bar holding the settlers was in-line with the prevailing current (i.e., tees were placed on the south side of each coral in an east-to-west current regime). On each PVC tee, three microscope slides were placed in a row to form one experimental replicate, which contained multiple coral settlers. Tees were placed next to adult coral colonies of three species: M. faveolata, Siderastrea siderea (massive starlet coral), and Diploria strigosa (symmetrical brain coral). Controls were placed in open areas of the same sand flat. A total of 113 settlers were deployed. Final survivorship was scored after four days.

\section{Microbe counts on the reef}

On three consecutive days, water samples were collected with sterile $15-\mathrm{mL}$ conical tubes $15 \mathrm{~cm}$ above the benthos at each experimental distance up- and down-current from one of the adult corals used in the distance-dependence field experiment, yielding complete microbial profiles up- and down-current from three adult coral colonies. On these same sampling days, water was also collected at the 96-cm distance up- and downcurrent from each of six other experimental corals. Water sampling was conducted three weeks after the distance-dependence survivorship experiment was completed. Meteorological data confirm that a consistent, east-to-west, wind-driven current occurred on each day of experimentation and water sample collection (Curaçao Port Authority, Willemstad Harbor data buoy). All water samples were fixed with paraformaldehyde (final concentration $2 \%$ volume/volume) within $30 \mathrm{~min}$ of collection. Microbes were visualized using standard epifluorescence microscopy methods for coral reef water samples (as in Dinsdale et al. 2008). At least 20 fields of view were analyzed for each sample (NIH ImageJ; available online). ${ }^{6}$

\section{Laboratory experiments}

Using the Janzen-Connell hypothesis as a framework, we set out to test whether a microbial component of the seawater surrounding adult coral colonies drove the patterns of juvenile mortality we observed in the field experiments and to determine whether water collected near adult corals of different species caused different degrees of mortality. To test these ideas, we conducted four separate laboratory experiments between 2007 and 2009. Each laboratory experiment was conducted using swimming $M$. faveolata planula larvae in experimental petri dish replicates, an approach we have used in previous studies to test for the factors that cause juvenile coral mortality (Vermeij et al. 2006, 2009). Planulae were incubated in various water samples collected from the experimental reef (schematic shown in Fig. 1E). To create water treatments, water was sampled from the experimental reef (Carmabi Buoy Zero) within $2 \mathrm{~cm}$ of the surface of the coral colonies. Samples were taken in triplicate, i.e., equal volumes of water were collected near three separate adult colonies of the same coral species and these samples were then pooled to create the treatment water. In each experiment, a different subset of reef habitats was sampled to create water treatments (e.g., up-current, down-current, $1 \mathrm{~cm}$ from adult conspecifics, and $1 \mathrm{~cm}$ from adults of other coral species). To reduce microbial numbers in some treatments, water samples were subject to filter sterilization

\footnotetext{
${ }^{6}$ http://rsbweb.nih.gov/ij/
} 


\section{A) Juvenile $M$. faveolata polyp}

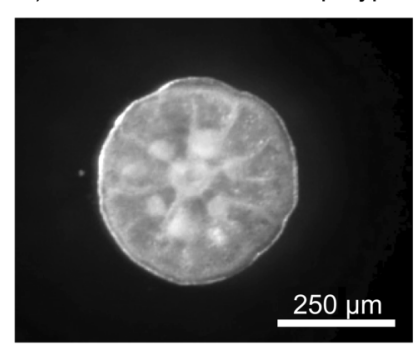

B) Method for deploying settled coral polyps to reef

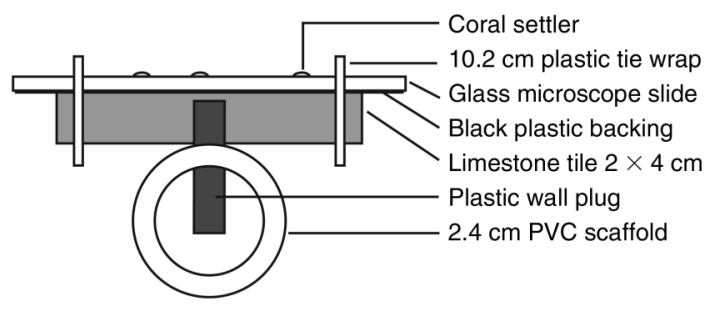

C) Distance-dependence field experiment with settlers and conspecific adults

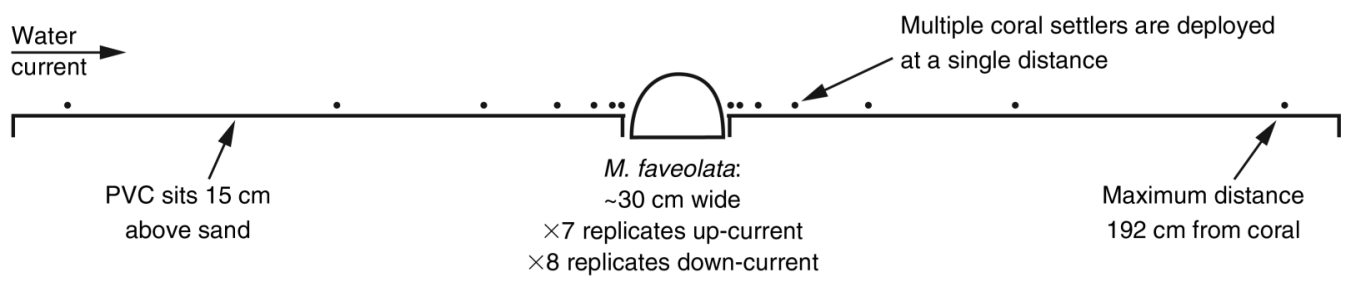

D) Host-specificity field experiment with settlers and different adult coral taxa

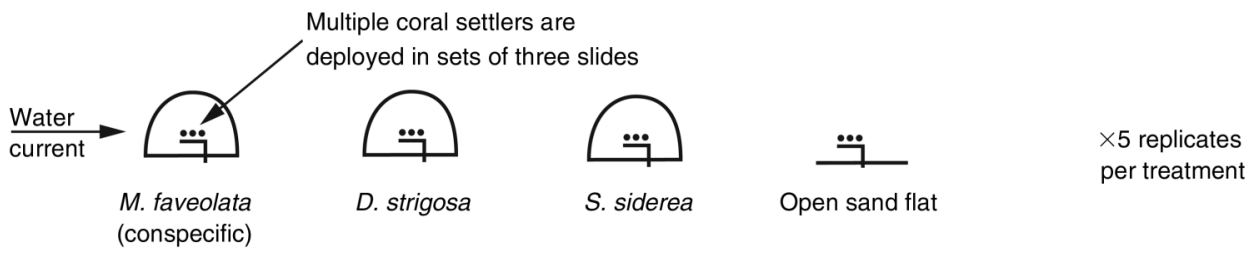

E) Water sampling locations for laboratory experiments with planulae
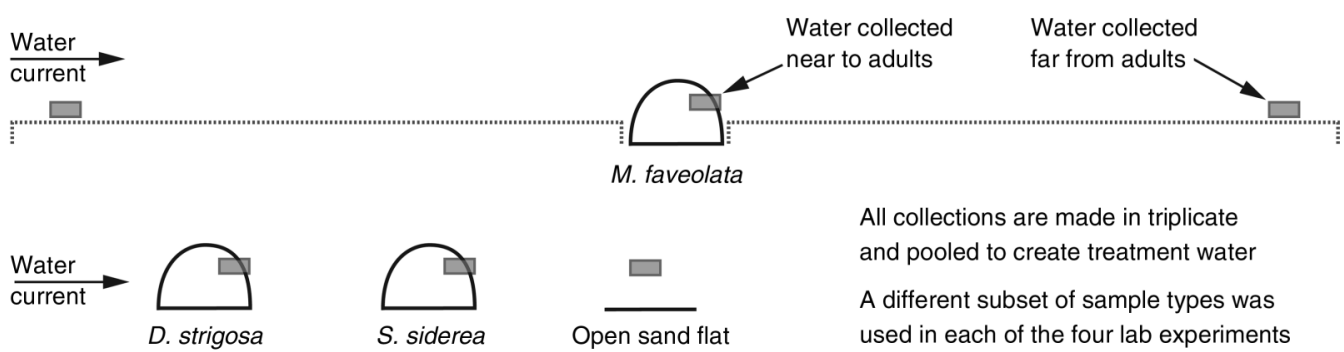

FIG. 1. Schematic of experimental methods used in field and laboratory experiments. (A) Settled polyp of the focal species, Montastraea faveolata. (B) Method for deploying settled coral polyps to various locations on the reef. (C) Schematic of distancedependence field experiment using conspecific adult coral colonies. (D) Species-specificity field experiment using adults of three different coral genera (Montastraea, Siderastrea, and Diploria) with controls placed in open areas of the same sand flat. (E) Water sampling locations used to create water treatments for various laboratory experiments. Each of the four laboratory experiments employed a different subset of these potential water collection locations.

(Sterivex 0.22 $\mu \mathrm{m}$; EMD Millipore, Billerica, Massachusetts, USA), treated with broad-spectrum antibiotics (66 $\mu \mathrm{g} / \mathrm{mL}$ penicillin), or both.

For a given experiment, swimming planulae were reared from a single population of fertilized embryos in multiple plastic containers. Prior to deployment into experimental replicates, planulae were pooled from multiple containers in order to create a single population of planulae for allocation into experiments. (Thus, any subtle environmental differences in rearing conditions between individual bins would not bias experimental outcomes.) Planulae were rinsed twice with sterile seawater (Sterivex $0.22 \mu \mathrm{m}$-filtered) to dislodge any loosely associated microbes. Planulae were then allocated randomly into experimental replicates $(10-\mathrm{cm}$ petri dishes). All experiments were conducted at low densities, $\leq 1$ larva $/ \mathrm{mL}$ seawater. This starting density, in which coral planulae occupy $<0.0001 \%$ of the water volume, is 
sufficiently low to allow long-term survival of planula larvae from spawning corals while lending sufficient statistical power to detect significant survivorship differences (e.g., Vermeij et al. 2006, 2009).

All experiments were arranged in a randomized block design; each experimental block contained one replicate petri dish from each treatment and the location of each replicate within the block was assigned using a random number generator. Thus the only known differences between blocks were their physical location on the laboratory bench and the arrangement of treatment dishes therein. This experimental design best accounts for any environmental gradients (e.g., light, temperature) that occur in a laboratory setting by ensuring that these factors do not generate spurious treatment effects or obscure real ones (Hurlbert 1984). Surviving and settled individuals were counted at regular intervals. Settlers were considered those that attached to the dish and had begun calcification.

\section{Statistical analysis}

General approach.-We used survivorship data taken over the course of each experiment to compare the relative fits of different demographic models. In all experiments, replicates contained multiple coral settlers/ planulae; this experimental design thus lends the statistical power to examine whether treatment conditions affect the proportion of individual corals surviving. In addition, the individual corals within a given replicate provide a second level of statistical power to test the effects of treatment conditions on survivorship. In the distance-dependence field experiment, replicates had different numbers of coral settlers to begin with and tiles were assigned to treatment distances randomly; with these data we were able to test for the effect of local settler density on survivorship. In all experiments, the survivorship of individuals was assumed to be a result of treatment conditions, with the fate of each individual settler/planula assumed to be independent of the fate of the others in a given replicate.

Given the probabilistic structure of binomial survivorship data, a likelihood approach was employed to find the best-fit demographic model that described each of the observed data sets (after Hilborn and Mangel 1997). The statistical fits of multiple models describing distinct hypotheses and groupings of data were compared, and the best-fit parameter values for the most supported model were identified. Analogous to parametric tests of differences among multiple means (e.g., ANOVA), we tested for differences among treatments in estimated survivorship. Further, we identified the most parsimonious model of groupings, analogous to results of Tukey's honestly significant difference post hoc tests. For experiments with four treatments or less, all possible parameter combinations were examined. For experiments with five or more treatments, parameter combinations were not examined exhaustively; rather, a starting model with the maximum number of degrees of freedom was analyzed first. Then, increasing numbers of constraints were placed on the parameters until the best-fit model was identified.

Treatment effects were considered significant when the data were best explained by multiple values for a given demographic parameter, given the penalty for added parameters. When two models had unequal numbers of parameters, likelihood ratio tests (for nested models) or AIC (for non-nested models) were used to select the best model. When two models had an equal number of parameters, the best combination of parameters was selected based on an assumption of equal Bayesian prior expectations (Sandin and Pacala 2005).

All $P$ values reported here represent the significance level of a comparison between the best-fit model and the next-best-fit model. Confidence intervals and standard error values were calculated for each demographic parameter within the likelihood model. For all analyses, we estimated the best-fit parameters in R ( R Development Core Team 2007) using the Nelder-Mead optimization algorithm. Additional details of the statistical analyses conducted for this study, including parameter estimates and likelihood values, are provided in the Appendix: Tables A1-A7.

Distance- and direction-dependence field experiment.This data set contained six consecutive days of survivorship data from coral settlers placed at 14 different experimental distances (i.e., seven distances in each direction, up-current and down-current from conspecific adults). We first analyzed each experimental distance independently to determine the best-fit survivorship probability at that given distance. The standard errors around these individual estimates are shown in Fig. 2A. Coral planulae settle unevenly on experimental tiles and we sought to maximize statistical power at the tile level (by maintaining the most settlers possible per tile); therefore the experimental design needed to account for variation in distance and direction from adult (treatment levels) as well as the number of settled polyps per replicate tile. Given these two forms of variation and the emergent statistical power, we tested whether direction (i.e., whether a settler was placed upcurrent vs. down-current from an adult) affected survivorship. Based on the predictions of the JanzenConnell hypothesis, we expected settlers on tiles placed up-current of the adult corals to have higher survivorship than those on tiles placed down-current. In addition, because the number of settlers per tile could affect survival, density was also formally considered as a cofactor. Therefore, we tested statistically for the interactive effects of direction and settler density on survivorship. To do this, we determined the relative fits of a set of complementary binomial regression models. The survivorship probability $s_{i}$ for a given replicate $i$ with density $\rho_{i}$ was described as follows: $s_{i}=\alpha \exp \left(\beta \rho_{i}\right)$. In this model, $\alpha$ and $\beta$ are the estimated parameters; $\alpha$ represents the daily probability of settler survivorship in the absence of density dependence and $\beta$ is the density- 

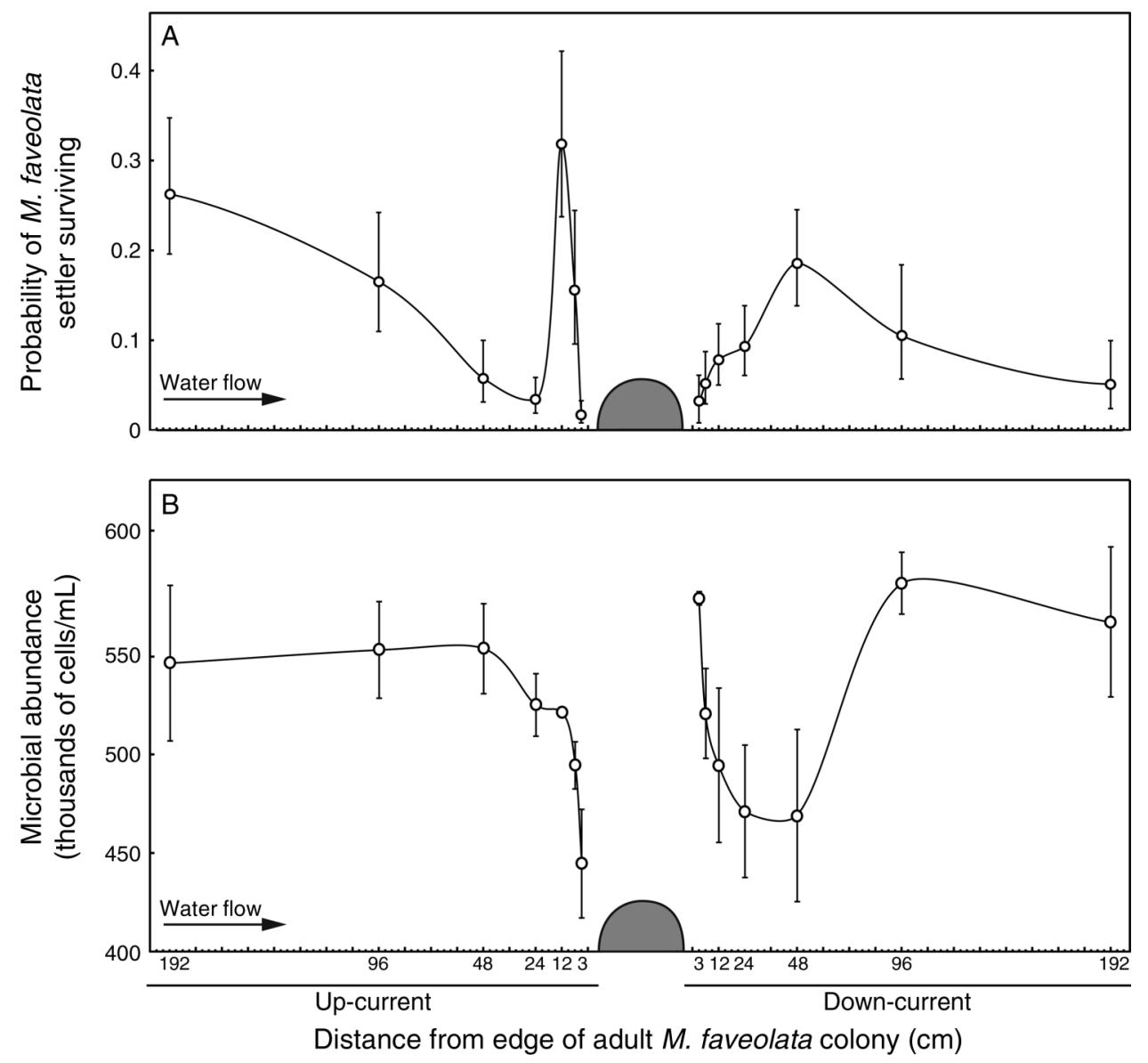

FIg. 2. Profiles of coral settler survivorship and microbial abundance around conspecific adult coral colonies. (A) Probability of survival (mean $\pm \mathrm{SE}$ ) of $M$. faveolata settlers placed at seven distances up- and down-current from adult $M$. faveolata colonies $(n$ $=7$ up-current, $n=8$ down-current, 445 total settlers, six-day experiment). Mortality was higher in the down-current direction than the up-current direction $(P=0.001)$, and mortality of juveniles was dependent on starting juvenile density $(P=0.019$; see Materials and Methods: Statistical analysis and Appendix: Table A1). The overall strength of this density dependence was stronger in the down-current direction. (B) Microbial density (mean \pm SE) up- and down-current from the same adult coral colonies depicted in panel (A) ( $n=3$ except at $96-\mathrm{cm}$ distances, where $n=7$ ). For both panels, the line is shown only to guide the eye.

dependent term. We estimated these parameters with various constraints applied to the model to determine the separate and interactive effects of direction and starting density on juvenile survival. To determine whether there was an effect of direction on juvenile survival, we tested whether two different values of $\alpha$ $\left(\alpha_{\text {up }}, \alpha_{\text {down }}\right)$ described the observed data better than one universal value of $\alpha$ (i.e., $\alpha_{\text {up }}=\alpha_{\text {down }}$ ). To determine whether there was an effect of starting juvenile density on survivorship, we tested whether a model with a density-dependent term $\left(\beta_{\text {up }}=\beta_{\text {down }} \neq 0\right)$ fit the data better than a model with no density dependence $\left(\beta_{\text {up }}=\right.$ $\beta_{\text {down }}=0$ ). To examine interactive effects between density and direction, we tested whether a model with different density-dependence parameters in either direction $\left(\beta_{\text {up }}, \beta_{\text {down }}\right)$ fit the observed data better than a model with a single density-dependence parameter $\left(\beta_{\text {up }}\right.$ $\left.=\beta_{\text {down }}\right)$. The best-fit model was one with separate density-dependent terms for the up-current vs. down- current directions. The estimated parameter values and likelihood values for these analyses are presented in the Appendix: Table A1.

Microbial abundance in the field.-To test whether microbial abundance in the field was correlated with coral settler survivorship, a Spearman rank correlation analysis was conducted using all data together $(n=14$; one-tailed test), and with up-current data analyzed separately from down-current data ( $n=7$; one-tailed test).

Laboratory experiments.-Four separate laboratory experiments were conducted. In all experiments, the starting density of swimming planula larvae was held constant between treatments and replicates; thus the demographic models considered did not include a density-dependence parameter. For all four experiments, survivorship was scored at regular intervals through time and the full set of observational data was used to estimate demographic parameters. The intervals of 
observation varied between experiments (three experiments were scored daily while a fourth was scored every five days); however in all models, the data were used to estimate the daily probability of mortality and the $95 \%$ confidence intervals around this probability. For all laboratory experiments, the proportion of juveniles surviving each time step was assumed to be determined by a single demographic parameter, $\mu_{x}$, the daily probability of juvenile mortality $\mu$ for treatment $x$. Numbers of individuals surviving in each replicate were assumed to be binomially distributed based on starting number and probability of survivorship $\left(1-\mu_{x}\right)$. Using the likelihood methods described in Statistical analysis: General approach, we determined the best-fit values of models with different parameter combinations (that is, different constraints on the value of $\mu_{x}$ ) with the goal of determining the most parsimonious combination of parameter values to describe the observed data. The initial model allowed all values of $\mu_{x}$ to vary freely; subsequent models constrained these values by forcing a common value of $\mu$ onto various groups of treatments. The best-fit model was determined as described in Statistical analysis: General approach. For the survivorship experiment depicted in Fig. 5, we also calculated the probability that surviving planulae would successfully settle (Fig. 8). These probabilities were calculated in a manner identical to that used for survivorship probabilities, with the exception that only data from the final day of observation were used (i.e., we determined $t_{x}$, the probability $t$ that a surviving planula in treatment $x$ had settled by day 23). The estimated parameter values and likelihood values for the laboratory experiments are presented in the Appendix: Tables A3-A7.

Species-specificity field experiment.-For this field experiment, settled coral polyps were deployed to the reef and survivorship was scored at a single time point, four days after deployment. The data were analyzed as described in Statistical analysis: Laboratory experiments for the laboratory experiments, using this single fourday time step to estimate $\mu_{x}$, the daily probability of mortality $\mu$ for treatment $x$. The estimated parameter values and likelihood values for this field experiment are presented in the Appendix: Table A2.

\section{RESULTS}

\section{Spatially structured mortality of juvenile corals in the field}

We first tested whether juvenile corals suffer distance-, direction-, or density-dependent mortality by deploying laboratory-reared coral settlers to a shallow reef with a consistent directional current (general methods are shown in Fig. 1A, B). A total of 445 three-week-old settlers were placed on the reef at seven distances upcurrent and down-current from eight conspecific adult corals in an open sand flat (Fig. 1C). In both the upcurrent and down-current directions, the survivorship patterns were complex, and survivorship did not increase steadily with distance as predicted by the
Janzen-Connell model (Fig. 2A); however survivorship patterns were qualitatively similar across all eight replicate coral colonies, and survivorship did vary between distances. In the up-current direction, the probability of survivorship was 15.4 times higher at the farthest distance $(192 \mathrm{~cm})$ from the adult colonies than at the closest distance (3 cm; Fig. 2A). Overall, survivorship in the up-current direction (with all seven distances pooled) was significantly higher than survivorship in the down-current direction (Fig. 2A, $P=$ 0.001; Appendix: Table A1).

The replicates in this experiment had a range of starting juvenile densities and were randomly assigned to treatment distances; we therefore tested for the effects of local settler density on juvenile mortality. We also tested for an interaction between direction and starting density (i.e., we tested whether direction from the coral affected the degree to which density dependence affected mortality). Juveniles suffered increased mortality with increased density of settlers and this density dependence was stronger in the down-current direction (Fig. 2A, $P=$ 0.019; Appendix: Table A1).

\section{Spatially structured seawater microbial communities surrounding adult corals}

Given the spatially structured patterns of coral settler survivorship near adult colonies, we examined whether reef microbial communities were also structured around these colonies. Using fluorescent microscopy, we quantified the total abundance of microbes (Bacteria and Archaea) on the experimental reef at the same distances where settler survivorship was measured (Fig. 2B). As with settler survivorship, microbial abundance varied with distance and direction from the adult corals in a complex manner but the pattern of microbial abundance was qualitatively similar between replicates (Fig. 2B). The lowest microbial abundance occurred immediately up-current $(3 \mathrm{~cm})$ from the coral heads. The highest microbial abundance occurred immediately down-current from the coral heads $(3 \mathrm{~cm})$ and at 96 and $192 \mathrm{~cm}$ distances down-current from the coral heads. Juvenile survivorship was also relatively low at these distances down-current; however microbial abundance and survivorship were not correlated in the up-current direction alone, down-current direction alone, or overall (Spearman rank correlation: up-current $n=7, r_{\mathrm{S}}=0$; downcurrent $n=7, r_{\mathrm{S}}=0.679$; overall $n=14, r_{\mathrm{S}}=0.213 ; P>$ 0.05 for all correlations). Thus, seawater microbial abundance per se is not correlated with coral settler mortality. Rather, these data reveal that potential biotic enemies of juvenile corals (waterborne microbes) are structured in the water column surrounding adult coral colonies at the same spatial scale as juvenile mortality.

\section{Taxon-specific mortality of juvenile corals in the field}

To test whether juvenile mortality near adult corals was dependent on the identity of the coral colony nearby, we placed newly settled $M$. faveolata polyps 


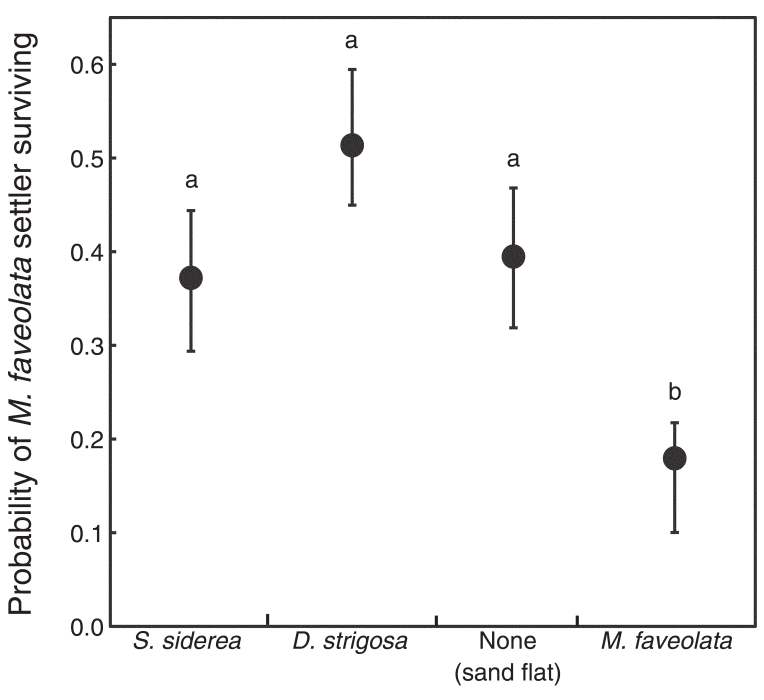

Species of nearby adult coral

FIG. 3. Survivorship of settled $M$. faveolata polyps deployed near adult corals of three different species. Different lowercase letters denote treatments with significantly different probabilities of mortality in a likelihood-based model (see Materials and methods: Statistical analysis and Appendix: Table A2). The probability of survivorship was significantly lower in the presence of conspecific adults than in the presence of other coral species or in open areas of the same reef $(P=0.004$; Appendix: Table A2). Vertical bars denote $95 \%$ CI, $n=5$, fourday experiment.

within $2 \mathrm{~cm}$ of adult colonies of three different genera and in open areas of the same sand flat (schematic is shown in Fig. 1D). As predicted by the Janzen-Connell hypothesis, survivorship was lowest for settlers placed next to conspecific adults (Fig. 3). The average probability of survivorship was 2.3-3.0 times higher when juveniles were placed near other coral genera and 2.4 times higher in open areas $(P=0.004$; see statistical results in Appendix: Table A2). This demonstrates in situ that mortality of coral settlers near adult colonies is constrained by the identity of the nearby adult coral.

\section{Distance-dependent, taxon-specific, microbe-mediated juvenile coral mortality in the laboratory}

The Janzen-Connell hypothesis predicts that juvenile mortality near adults is caused by a host-specific biotic agent (i.e., a pathogen/predator whose action is limited to a certain host species, host genus, functional group, or a restricted phylogenetic distance) and that this agent is most harmful to juveniles of the same taxon. We hypothesized that (1) seawater near conspecific adult corals would cause greater mortality to juveniles than seawater collected farther away, (2) seawater collected near adult corals would cause increased mortality compared to seawater collected near other genera of corals, and (3) these effects were due to a microbial component of the seawater (i.e., bacteria shed from the adult corals). To test these predictions, we conducted four laboratory experiments in which swimming, presettlement $M$. faveolata planulae were incubated in various water samples collected from locations across the reef (see schematic in Fig. 1E for types of water collections made).

In the first laboratory experiment, we examined survivorship of swimming $M$. faveolata planulae in water collected near and far from conspecific adult corals; half of each water collection was filter sterilized $(0.22 \mu \mathrm{m}$ Sterivex) to remove microbes from the water, creating four separate treatments: near $M$. faveolatal unfiltered, near M. faveolata/sterilized, up-current/unfiltered, and up-current/sterilized. Survivorship was significantly lower in the near $M$. faveolata/unsterilized water treatment than in all three other treatments, demonstrating distance-dependent mortality of conspecific juveniles that can be attributed to the microbial fraction of seawater near conspecific adult colonies (Fig. 4, $P=0.004$; Appendix: Table A3).

In the second laboratory experiment, we examined survivorship of swimming $M$. faveolata planulae in water collected near adult coral colonies of four different genera (Porites astreoides, Siderastrea siderea, Diploria strigosa, and the conspecific $M$. faveolata) as well as in water collected in open reef areas up-current from conspecific corals (Fig. 5). Swimming M. faveolata

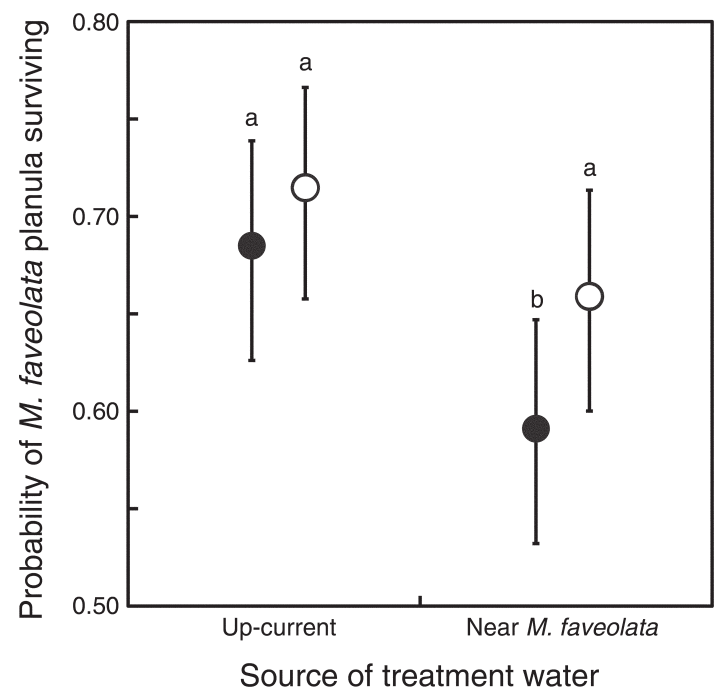

FIG. 4. Effects of distance and microbes on survivorship of M. faveolata planula larvae. Presettlement planulae were treated in the laboratory with water collected near conspecific adult colonies and up-current from the same colonies. Solid circles denote raw water; open circles, filter-sterilized water. Different lowercase letters denote treatments with significantly different probabilities of mortality in a likelihood-based model (see Materials and methods: Statistical analysis and Appendix: Table A3). Planulae treated with raw water collected near conspecific adults had a significantly lower probability of survivorship than planulae in water collected up-current; this effect was not observed when microbes were removed from the water using filter sterilization ( $P=0.004$; Appendix: Table A3). Vertical bars denote $95 \%$ CI, 10 planulae per replicate, $n=26$, seven-day experiment. 


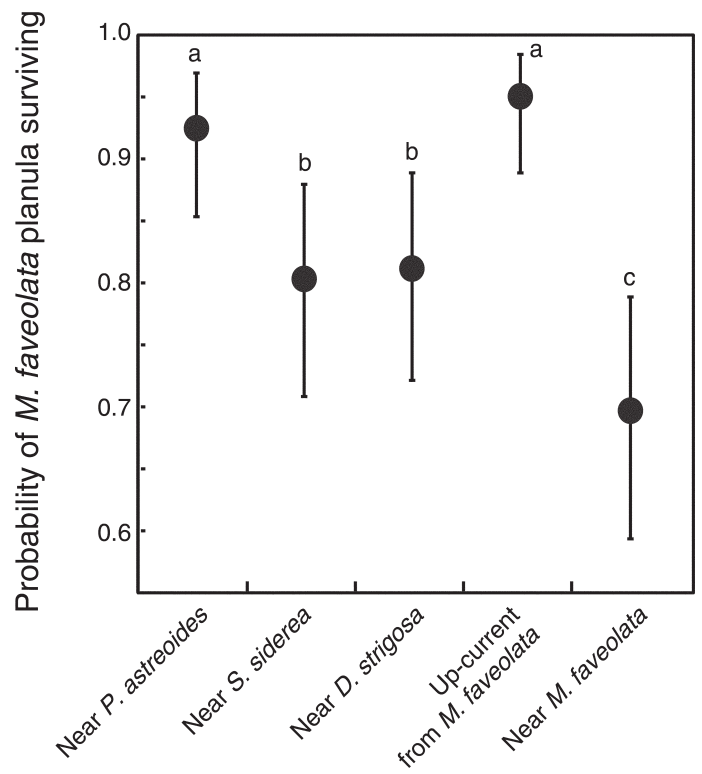

\section{Source of treatment water}

FIG. 5. Effects of distance and adult coral genus on survivorship of $M$. faveolata planula larvae. Presettlement planula larvae were treated in the laboratory with water collected near adult coral colonies of four different genera and up-current from conspecific adult colonies. In this experiment, all water samples were used raw, not filter sterilized. Lowercase letters denote treatments with significantly different probabilities of mortality in a likelihood-based model (see Materials and methods: Statistical analysis and Appendix: Table A4). Planulae treated with water collected near conspecific adults had a significantly lower probability of survivorship than planulae in any other treatment $(P<0.001$; Appendix: Table A4). Vertical bars denote $95 \%$ CI, 40 planulae per replicate, $n=5$, 15-day experiment.

planulae suffered significantly lower survivorship in water collected near conspecific adults than in all other treatments $(P<0.001$; Appendix: Table A4), demonstrating that near-coral mortality is distance-dependent, taxon-specific, and can be mediated by a factor in the microbial fraction of the seawater.

In the third laboratory experiment, we examined survivorship of swimming $M$. faveolata planulae in water collected from four reef locations: near $M$. faveolata, near D. strigosa, up-current from M. faveolata, and down-current from M. faveolata (Fig. 6). Each water treatment was repeated with both raw and filtersterilized $(0.22 \mu \mathrm{m}$ Sterivex $)$ water. Survivorship was significantly lower in water collected near to or downcurrent from $M$. faveolata colonies; survivorship was significantly higher when this water was filter sterilized $(P=0.001$; Appendix: Table A5). Survivorship was also significantly higher in water collected up-current from M. faveolata colonies or near D. strigosa. These results demonstrate distance-dependent and direction-dependent, taxon-specific juvenile coral mortality that is mediated by the microbial fraction of the seawater.
In the fourth laboratory experiment, we examined survivorship of swimming $M$. faveolata planulae in water collected in four locations: near $S$. siderea, near $D$. strigosa, up-current from M. faveolata, and near $M$. faveolata. Water collected near M. faveolata was also treated with filter sterilization, antibiotics (penicillin, 66 $\mu \mathrm{g} / \mathrm{mL}$ ), or both, to reduce the number of microbes (Fig. 7). Survivorship was significantly lower in water collected near conspecifics than in water collected near other coral species or up-current from conspecifics $(P=$ 0.04; Appendix: Table A6). Survivorship in water collected near conspecifics was also significantly higher when this water was filter sterilized or treated with both filter sterilization and antibiotics. Antibiotic treatment alone increased survivorship slightly, but this effect could not be resolved statistically, largely due to high overall survivorship in this experiment. Overall, these data provide additional evidence that juvenile coral mortality is distance-dependent, taxon-specific, and mediated by a microbial component of the seawater near adult corals.

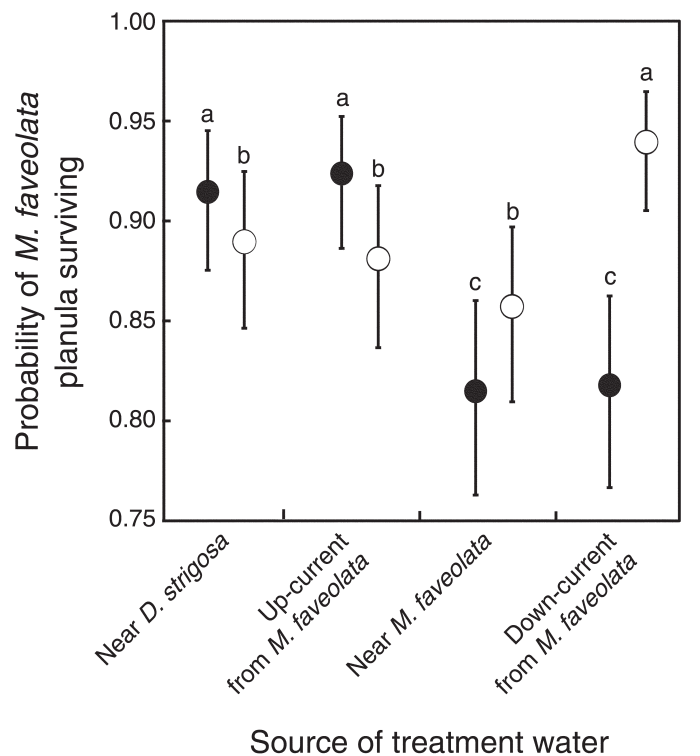

FIG. 6. Effects of distance, adult coral genus, and microbes on survivorship of $M$. faveolata planula larvae. Presettlement planula larvae were treated in the laboratory with water collected from four reef habitats: near adult Diploria strigosa colonies, near conspecific adult colonies, and both up-current and down-current from the conspecific colonies. Solid circles denote raw water; open circles, filter-sterilized water. Different lowercase letters denote treatments with significantly different probabilities of mortality in a likelihood-based model (see Materials and methods: Statistical analysis and Appendix: Table A5). The probability of survivorship was lowest for planulae in raw water collected near conspecific adult colonies and downcurrent from these colonies; at both of these distances survivorship increased significantly when water was filter sterilized to remove microbes $(P=0.001$; Appendix: Table A5). Vertical bars denote $95 \%$ CI, 25 planulae per replicate, $n=$ 10, 14-day experiment. 


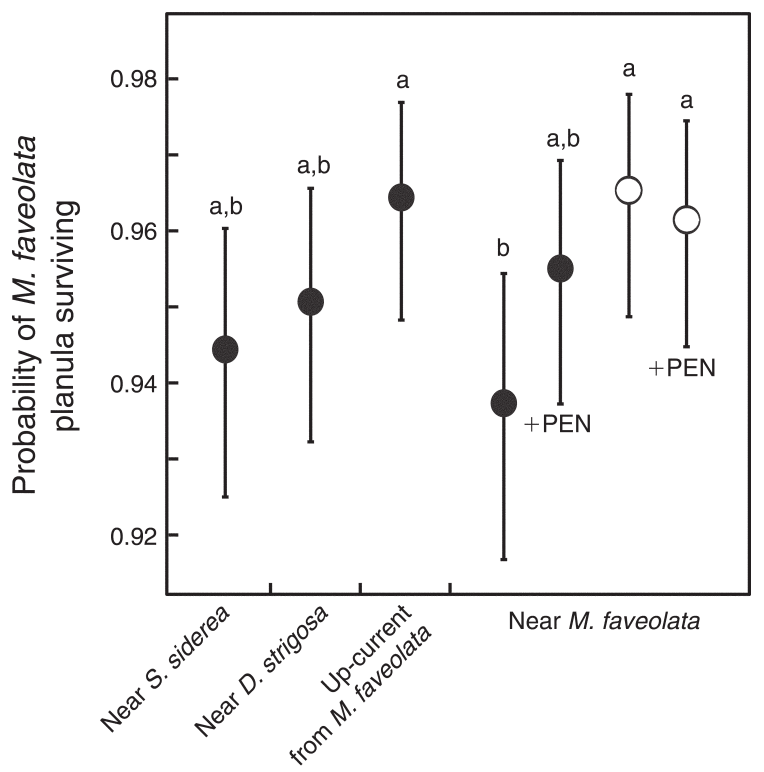

Source of treatment water

FIG. 7. Effects of distance, adult coral genus, and microbes on survivorship of $M$. faveolata planula larvae. Presettlement $M$. faveolata planula larvae were treated in the laboratory with water collected from one of four reef habitats: near adult colonies of three different coral genera and up-current from conspecific corals. Solid circles denote raw water; open circles, water samples that were treated with filter sterilization; + PEN, water samples that were treated with penicillin. Different lowercase letters denote treatments with significantly different probabilities of mortality in a likelihood-based model (see Materials and methods: Statistical analysis and Appendix: Table A6). The probability of survivorship was significantly lower in water collected near conspecifics compared to water collected up-current or water that was filter sterilized $(P=0.04$; Appendix: Table A6). The effects of the remaining treatments on survivorship could not be resolved statistically due to high overall survivorship in the experiment; however, the differences in survivorship probabilities are consistent with the trends observed in all other field and laboratory experiments. Vertical bars denote $95 \%$ CI, 40 planulae per replicate, $n=16$, seven-day experiment.

\section{Species-specificity of larval settlement}

In one laboratory survivorship experiment (depicted in Fig. 5), planulae were maintained in water collected near different coral species for a longer period of time, until differences in settlement rates became apparent (23 days; Fig. 8). Data are presented as the probability of a surviving larva settling in each treatment; however the same pattern was also seen in the absolute number of settlers in each treatment. The lowest settlement rate was observed in planulae exposed to water from conspecific corals. Settlement was 5.1-11.2 times higher in water collected near other species of corals and 11 times higher in water collected in the open reef flat. Overall, $M$. faveolata planulae were significantly less likely to settle in water collected near conspecifics as compared to water collected near $P$. astreoides, $S$. siderea, or $D$. strigosa, or in water collected up-current from $M$. faveolata ( $P=0.027$; Appendix: Table A7). Thus, it appears that swimming $M$. faveolata juveniles may avoid or delay settlement when in close proximity to conspecific adults.

\section{Discussion}

\section{Janzen-Connell effects in a reef coral}

We used the abundant Caribbean coral Montastraea faveolata to test three major predictions of the JanzenConnell hypothesis: that juveniles suffer distance- or density-dependent mortality near conspecific adults, that this effect is taxon-specific, and that this effect is mediated by host-specific biotic enemies (in this case, microbes). In two field experiments and four laboratory experiments, we found evidence to support all of these predictions.

In the first field experiment, juvenile mortality and seawater microbial abundance were complex in pattern and highly structured at the same spatial scales (Fig. 2A, B). Though distance dependence per se was not clear from these complex patterns, we were able to detect a significant effect of direction and starting juvenile density (Fig. 2A). Janzen himself predicted seedlings

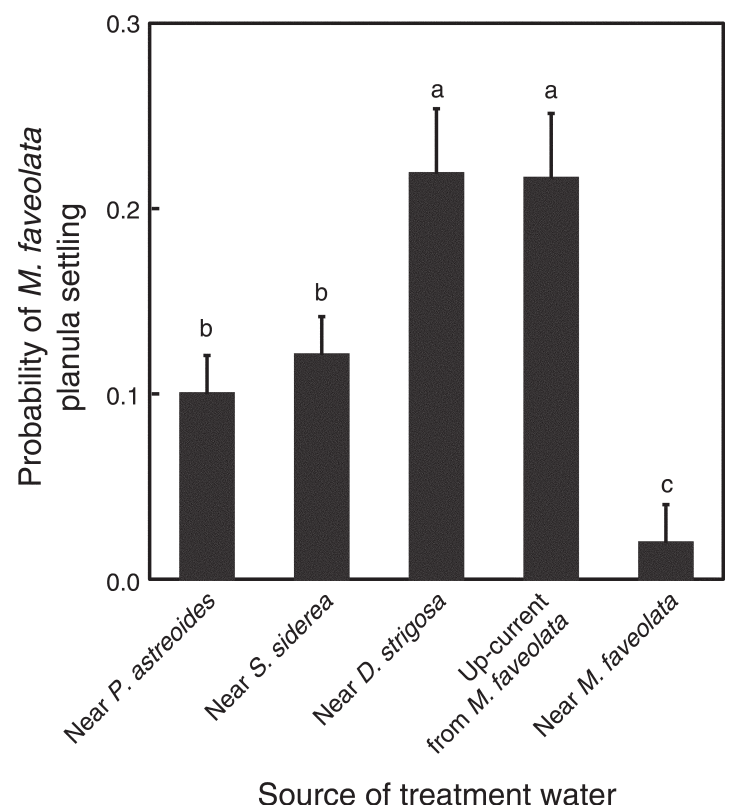

FIG. 8. Effects of distance and adult coral genus on settlement rate of surviving $M$. faveolata planula larvae. Presettlement planulae were treated in the laboratory with water collected near adult coral colonies of four different genera and up-current from conspecific adult colonies. In this experiment, all water samples were used raw (not filter sterilized). Different lowercase letters denote treatments with significantly different probabilities of settlement in a likelihoodbased model (see Materials and methods: Statistical analysis and Appendix: Table A7). Surviving planulae treated with water collected near conspecific adults had a significantly lower probability of settlement than larvae in any other treatment $(P$ $=0.027$; Appendix: Table A7). Vertical bars denote 95\% CI, 40 planulae per replicate, $n=5$, day 23 . 
would suffer density-dependent mortality (Janzen 1970), and this has been observed in both experimental (e.g., Packer and Clay 2000) and observational (e.g., Comita and Hubbell 2009) studies of seedling survivorship. In our second field experiment, settler mortality was dependent on the identity of the adult coral nearby (Fig. 3), providing support for the predictions that juvenile mortality is distance dependent and taxon specific.

In four laboratory experiments, we observed evidence for all three aspects of the Janzen-Connell hypothesis. (1) Survivorship of $M$. faveolata planulae was significantly reduced in water collected near conspecific adults when compared to water collected up-current from these adults (Figs. 4-7), providing support for the hypothesis that mortality is distance dependent near conspecifics. (2) Survivorship was significantly reduced in water collected near conspecifics when compared to water collected near corals of other genera (Figs. 5-7), providing support for the prediction that mortality is taxon specific. (3) Survivorship was significantly reduced in water collected near conspecific adults when compared to water treated with filter sterilization to remove microbes (Figs. 4, 6, and 7), providing support for the prediction that mortality is due to a host-specific biotic (microbial) enemy.

In the laboratory experiments, significant treatment effects were most difficult to resolve in the experiment with the highest overall survivorship (Fig. 7); this experiment was conducted with larvae from the healthiest reef (Playa Kalki). Nonsignificant survivorship differences were nevertheless consistent in direction with all other experiments we conducted. These results provide anecdotal evidence that the strength of JanzenConnell effects in corals (and the ability of ecologists to detect them on experimental timescales) will depend on the local health of coral adults and juveniles.

In sum, six separate experiments revealed that Montastraea faveolata juveniles suffered the highest mortality in close proximity to conspecific adults. Importantly, we did not observe any results in conflict with the predictions of the Janzen-Connell model. Thus, our findings represent the first test for (and first demonstration of) Janzen-Connell effects in the ocean and in an animal. These results highlight the generality of an ecological mechanism that promotes community diversity.

Although the original Janzen-Connell model predicted that the effect of adults on nearby juveniles would be species-specific, some studies of plants have found such effects occur instead at the level of plant functional groups (Petermann et al. 2008) or that these effects increase in strength with decreasing phylogenetic distance (Liu et al. 2011, Paine et al. 2011). Our experiments used corals from different genera; therefore it remains to be seen whether Janzen-Connell effects will be observed between coral species of a single genus. An intriguing possibility is that such effects not only occur at the species level in corals but that they have also helped facilitate and reinforce speciation processes in groups of closely related corals.

\section{Considering Janzen-Connell mechanisms in aquatic environments}

Extending a terrestrial ecological model to the marine realm reveals the ways in which the physical and biochemical nature of the habitat modify the underlying processes and predicted results of such a model. We observed complex patterns of juvenile survivorship that could not be easily explained with an equation or with the simple phrase "distance dependent," and we observed similarly complex patterns of microbial abundance.

For a given coral species, microbe shedding rates and residence times around a colony will be affected by colony shape (Kaandorp et al. 2003), surfactant molecules in mucus (Deacon 1979), rate of mucus production (Johannes 1967, Brown and Bythell 2005), and by water flow into the sediment around the colony (Hunter et al. 2006). Notably, the microbial patterns we observed were consistent with hydrodynamic models of flow around a cylinder. At certain Reynolds numbers, a cylinder in a unidirectional flow regime causes the shedding of small vortices from alternating sides of the cylinder, creating a resonance pattern (i.e., a Von Karman vortex street) and an area of reduced flow behind the cylinder, just beyond the boundary layer (König et al. 1993, Williamson 1996). Materials shed from the cylinder occur at their lowest concentration at intermediate distances. Thus, water flow around adult coral heads is predicted to create heterogeneous seawater habitats in which residence time and microbial abundance vary in a nonlinear and non-monotonic way. By extension, juvenile corals in such a flow regime will experience this microbial habitat heterogeneity; although survivorship will be spatially structured, it is not expected to be strictly distance dependent. It is possible that flow differences alone caused the survivorship patterns we observed (Fig. 2A); however this is highly unlikely because the most probable biotic enemies of the coral settlers (microbes) were also spatially structured around the adult corals, and we observed survivorship differences in all five follow-up experiments that could not be explained by differences in flow.

\section{Host-specific microbes as spatially structured biotic enemies}

In both coral reefs and rain forests, many potential causes of propagule mortality cannot be easily observed or disentangled through field observations or field experiments alone. This makes our laboratory experiments a powerful complement to the field experiments because laboratory conditions excluded all physical (e.g., shading, water flow) and predatory (e.g., invertebrate predation/grazing, fish scraping/browsing) sources of mortality that might operate in a spatially structured 
manner around a coral colony on a reef. In the laboratory experiments (Figs. 3-7), we showed that mortality of juvenile corals in close proximity to conspecific adult corals was caused by the microbial fraction of the water surrounding the adult colonies. Possible sources of mortality in these water packets include microbes, viruses, and allelopathic chemicals. While all factors may affect juvenile survival, we were able to rescue survivorship through the physical removal of the microbial fraction of seawater, making microbes themselves the most likely cause of mortality in our experiments. Host-specific microbes in the boundary layers near adult coral colonies could therefore represent the marine analogues of the host-specific enemies responsible for Janzen-Connell effects in terrestrial systems.

Coral mucus and the bacterial assemblage it hosts are known to be largely specific to the host coral species or genus and both mucus and microbes will be shed into the water column around an adult coral (Crossland 1987, Coffroth 1990, Wild et al. 2004, Brown and Bythell 2005, Ritchie 2006, Johnston and Rohwer 2007 , Allers et al. 2008, Tremblay et al. 2011). In our experiments, mortality may have been caused by the transfer of specific pathogenic microbes from adults to juveniles and/or the increased activity of water column or juvenile-associated microbes due to the presence of particulate organic carbon (i.e., mucus) from the adult corals. Nevertheless, under either mechanism, mortality is attributable to host-specific microbial activity caused by the presence of a conspecific adult.

\section{Microbes as potential navigational cues for coral larvae}

As swimming planulae, corals employ a complex set of searching and tasting behaviors to choose a settlement habitat (Ritson-Williams et al. 2009), and they can distinguish between individual molecules (Morse and Morse 1991) as well as biofilms formed at different depths (Baird et al. 2003). Our data show that coral planulae may similarly distinguish between water column microbial environments near adult corals of different genera (Fig. 8). Larvae of many marine species are known to preferentially choose low-mortality settlement habitats (Grosberg 1981); however our observations suggest a previously undescribed form of habitat discrimination in corals. This behavior (in addition to the survivorship patterns we report here) could structure the spatial patterning of coral communities from the very early stages of the coral life cycle.

\section{Extending the Janzen-Connell model to corals with different life history strategies}

We studied a mass-spawning coral capable of dispersing hundreds of kilometers during the larval phase. Juveniles of this species are not expected to settle in proximity to their parent colonies. Therefore, in all of our experiments, we collected juvenile corals from one of three reefs and conducted survivorship experiments with water collections and corals from a fourth reef. Other coral species (and a wide range of other reef invertebrates) show much stronger philopatry than our study species, releasing brooded larvae that may disperse only millimeters or centimeters from the adult colony before settlement (Jackson 1986). The range of dispersal strategies employed by corals reflects the trade-off between sending juveniles broadly to colonize new habitat and restricting the distance traveled to ensure a suitable habitat is encountered. The importance of the latter strategy is widely recognized in the theoretical literature of larval dispersal, and superficially seems to run counter to the notion of distance-dependent mortality. However, neither brooding reproductive modes nor philopatry in general eliminate the potential for Janzen-Connell effects to occur in a coral species; rather, the life history strategy of a coral species is expected to affect the spatial scale at which such effects occur.

In fact, the current study was motivated by observations of density-dependent mortality in a brooding coral (Siderastrea radians) whose dispersal distances are so short that $\sim 50 \%$ of settlers within a $0.5 \times 0.5$ m quadrat are produced by adults within the same quadrat (Vermeij 2005). That study and its follow-up work (Vermeij and Sandin 2008) demonstrated densitydependent and distance-dependent settlement and mortality in a brooding coral species, at a scale of millimeters to centimeters, with approximately half of these interactions occurring between parent and offspring. The results we present here demonstrate that mortality in a spawning coral species is spatially structured at a scale of centimeters (if not smaller) to meters, with $0 \%$ of these interactions occurring between parent and offspring. Thus, coral larval settlement to a habitat with conspecific adults may be beneficial at one scale (as conspecifics presumably occupy a habitat suitable for the species) but detrimental at smaller scales (where nearness to conspecifics, related or not, becomes a threat to survival). The point at which philopatry becomes dangerous for a settler will vary by species. Importantly, when examining patterns of juvenile settlement, it may be the case that some coral species have clumped distributions due to brooding reproductive modes, yet individuals may be less clumped than would be expected by chance (as is seen in some rain forest tree species; e.g., Wills et al. 2006) due to JanzenConnell effects.

In the case of coral species that reproduce primarily by fragmentation (such as the Caribbean species Acropora cervicornis and A. palamata), it is unclear whether Janzen-Connell effects will occur, and if so, at what spatial scale. While fragments of adult colonies may be expected to be more resistant to host-specific biotic enemies than are single-polyp juveniles, the exposed tissue wounds on recently broken fragments 
could also make this tissue susceptible to attack by microbes harbored on nearby adult colonies.

In sum, the assembly of coral communities is governed not only by larval supply on a scale of centimeters to kilometers, but also by species-specific dispersal and recruitment characteristics on the scale of millimeters to meters, and by taxon-specific microbial factors on a scale of microns to centimeters. Given that we observed Janzen-Connell effects in a common Caribbean reef coral, locally rare coral species are expected to have a survivorship advantage over this abundant species beginning at the settlement stage. Strong intraspecific density dependence (relative to interspecific density dependence) is a key to the creation and maintenance of biodiversity (Chesson 2000), and thus Janzen-Connell survivorship effects may help to explain why coral communities have high species diversity that has remained remarkably stable through geological time (Pandolfi and Jackson 2001, 2006).

Just as the distribution of seeds, seedlings, and adult trees provides clues to the processes maintaining forest diversity, the spatial structure of juvenile and adult coral populations across a reef will reveal how the processes we describe here apply to other coral species, including those whose juveniles are difficult to obtain and study experimentally. Because coral planulae can actively select their settlement locations, Janzen-Connell effects may be more apparent at early life history stages in coral communities than in tree communities. Coral reefs therefore provide ecologists with a setting in which to test the generality of an ecological theory of diversity while revealing the organism- and habitat-specific modifications that must be made to such a theory when it is taken underwater.

\section{ACKNOWLEDGMENTS}

We thank K. Barott, A. Hartmann, A. Johnson, E. Kelly, R. Trebilco, K. Withy-Allen, and T. Vardi for enthusiastic field assistance; L. Kelly, T. Samo, and S. Smriga for microscope access and advice; CARMABI staff in Curaçao for logistical support; C. Wills and J. B. C. Jackson for sharing insights from their work on rain forests and coral reefs; and three anonymous reviewers for providing helpful comments on an earlier draft of the manuscript. K. L. Marhaver was supported by NSF GRFP and IGERT fellowships and NSF Doctoral Dissertation Improvement Grant number 0910372. M. J. A. Vermeij was supported by the Government of Curaçao through its annual subsidy to the CARMABI Foundation and by the European Union under the Seventh Framework Program (grant number 244161).

\section{Literature Cited}

Allers, E., C. Niesner, C. Wild, and J. Pernthaler. 2008. Microbes enriched in seawater after addition of coral mucus. Applied and Environmental Microbiology 74:3274-3278.

Apprill, A., H. Q. Marlow, M. Q. Martindale, and M. S. Rappé. 2009. The onset of microbial associations in the coral Pocillopora meandrina. ISME Journal 3:685-699.

Augspurger, C. K. 1983. Seed dispersal of the tropical tree, Platypodium elegans, and the escape of its seedlings from fungal pathogens. Journal of Ecology 71:759-771.

Baird, A. H., R. C. Babcock, and C. P. Mundy. 2003. Habitat selection by larvae influences the depth distribution of six common coral species. Marine Ecology Progress Series 252:289-293.

Bell, T., R. P. Freckleton, and O. T. Lewis. 2006. Plant pathogens drive density-dependent seedling mortality in a tropical tree. Ecology Letters 9:569-574.

Brown, B. E., and J. C. Bythell. 2005. Perspectives on mucus secretion in reef corals. Marine Ecology Progress Series 296:291-309.

Buss, L. W., and J. B. C. Jackson. 1979. Competitive networks: nontransitive competitive relationships in cryptic coral reef environments. American Naturalist 113:223-234.

Carlon, D. B., A. F. Budd, and F. Bonhomme. 2002. Incipient speciation across a depth gradient in a scleractinian coral? Evolution 56:2227-2242.

Chesson, P. 2000. Mechanisms of maintenance of species diversity. Annual Review of Ecology and Systematics 31:343-366.

Coffroth, M. A. 1990. Mucous sheet formation on poritid corals: an evaluation of coral mucus as a nutrient source on reefs. Marine Biology 105:39-49.

Comita, L. S., and S. P. Hubbell. 2009. Local neighborhood and species' shade tolerance influence survival in a diverse seedling bank. Ecology 90:328-334.

Connell, J. H. 1971. On the role of natural enemies in preventing competitive exclusion in some marine animals and in rain forest trees. Pages 298-312 in P. J. Den Boer and G. R. Gradwell, editors. Dynamics of populations. Center for Agricultural Publishing and Documentation, Wageningen, The Netherlands.

Connell, J. H. 1978. Diversity in tropical rain forests and coral reefs. Science 199:1302-1310.

Crossland, C. J. 1987. In situ release of mucus and DOC-lipid from the corals Acropora variabilis and Stylophora pistillata in different light regimes. Coral Reefs 6:35-42.

Deacon, E. L. 1979. Role of coral mucus in reducing the wind drag over coral reefs. Boundary-Layer Meteorology 17:517521.

Dinsdale, E. A., et al. 2008. Microbial ecology of four coral atolls in the Northern Line Islands. PLoS ONE 3:e1584.

Dykhuizen, D. E. 1998. Santa Rosalia revisited: Why are there so many species of bacteria? Antonie Van Leeuwenhoek 73:25-33.

Efrony, R., I. Atad, and E. Rosenberg. 2009. Phage therapy of coral white plague disease: properties of phage BA3. Current Microbiology 58:139-145.

Frank, U., U. Oren, Y. Loya, and B. Rinkevich. 1997. Alloimmune maturation in the coral Stylophora pistillata is achieved through three distinctive stages, 4 months postmetamorphosis. Proceedings of the Royal Society B 264:99104.

Fukami, H., A. F. Budd, G. Paulay, A. Solé-Cava, C. A. Chen, K. Iwao, and N. Knowlton. 2004. Conventional taxonomy obscures deep divergence between Pacific and Atlantic corals. Nature 427:832-835.

Gilbert, G. S., S. P. Hubbell, and R. B. Foster. 1994. Density and distance-to-adult effects of a canker disease of trees in a moist tropical forest. Oecologia 98:100-108.

Grosberg, R. K. 1981. Competitive ability influences habitat choice in marine invertebrates. Nature 290:700-702.

Harvell, D., E. Jordan-Dahlgren, S. Merkel, E. Rosenberg, L. Raymundo, G. Smith, E. Weil, and B. Willis. 2007. Coral disease, environmental drivers, and the balance between coral and microbial associates. Oceanography 20:172-195.

Hilborn, R., and M. Mangel. 1997. The ecological detective: confronting models with data. Princeton University Press, Princeton, New Jersey, USA.

Hunter, E. M., H. J. Mills, and J. E. Kostka. 2006. Microbial community diversity associated with carbon and nitrogen cycling in permeable shelf sediments. Applied and Environmental Microbiology 72:5689-5701. 
Hurlbert, S. H. 1984. Pseudoreplication and the design of ecological field experiments. Ecological Monographs 54:187211.

Hutchinson, G. E. 1961. The paradox of the plankton. American Naturalist 95:137-145.

Jackson, J. B. C. 1986. Modes of dispersal of benthic invertebrates: consequences for species' distributions and genetic structure of local populations. Bulletin of Marine Science 39:588-606.

Jackson, J. B. C., and L. Buss. 1975. Allelopathy and spatial competition among coral reef invertebrates. Proceedings of the National Academy of Sciences USA 72:5160-5163.

Janzen, D. H. 1970. Herbivores and the number of tree species in tropical forests. American Naturalist 104:501-528.

Johannes, R. E. 1967. Ecology of organic aggregates in the vicinity of a coral reef. Limnology and Oceanography 12:189-195.

Johnston, I. S., and F. Rohwer. 2007. Microbial landscapes on the outer tissue surfaces of the reef-building coral Porites compressa. Coral Reefs 26:375-383.

Kaandorp, J. A., E. A. Koopman, P. M. Sloot, R. P. M. Bak, M. J. Vermeij, and L. E. Lampmann. 2003. Simulation and analysis of flow patterns around the scleractinian coral Madracis mirabilis (Duchassaing and Michelotti). Philosophical Transactions of the Royal Society B 358:1551-1557.

Kenyon, J. C. 1997. Models of reticulate evolution in the coral genus Acropora based on chromosome numbers: parallels with plants. Evolution 51:756-767.

Kline, D. I., N. M. Kuntz, M. Breitbart, N. Knowlton, and F. Rohwer. 2006. Role of elevated organic carbon levels and microbial activity in coral mortality. Marine Ecology Progress Series 314:119-125.

Knowlton, N., and J. B. C. Jackson. 1994. New taxonomy and niche partitioning on coral reefs: jack of all trades or master of some? Trends in Ecology and Evolution 9:7-9.

Knowlton, N., E. Weil, L. A. Weigt, and H. M. Guzman. 1992. Sibling species in Montastraea annularis, coral bleaching, and the coral climate record. Science 255:330-333.

König, M., B. R. Noack, and H. Eckelmann. 1993. Discrete shedding modes in the von Karman vortex street. Physics of Fluids A 5:1846-1848.

Koren, O., and E. Rosenberg. 2006. Bacteria associated with mucus and tissues of the coral Oculina patagonica in summer and winter. Applied and Environmental Microbiology 72:5254-5259.

Lang, J. C. 1973. Interspecific aggression by scleractinian corals. II. Why the race is not only to the swift. Bulletin of Marine Science 23:260-279.

Levitan, D. R., H. Fukami, J. Jara, D. Kline, T. M. McGovern, K. E. McGhee, C. A. Swanson, and N. Knowlton. 2004. Mechanisms of reproductive isolation among sympatric broadcast-spawning corals of the Montastraea annularis species complex. Evolution 58:308-323.

Liu, X., M. Lang, R. S. Etienne, Y. Wang, C. Staehelin, and S. Yu. 2011. Experimental evidence for a phylogenetic JanzenConnell effect in a subtropical forest. Ecology Letters 15:111-118.

Marhaver, K. L., R. A. Edwards, and F. Rohwer. 2008. Viral communities associated with healthy and bleaching corals. Environmental Microbiology 10:2277-2286.

Morse, D. E., and A. N. C. Morse. 1991. Enzymatic characterization of the morphogen recognized by Agaricia humilis (scleractinian coral) larvae. Biological Bulletin 181:104-122.

Packer, A., and K. Clay. 2000. Soil pathogens and spatial patterns of seedling mortality in a temperate tree. Nature 404:278-281.

Paine, C. E. T., N. Norden, J. Chave, P.-M. Forget, C. Fortunel, K. G. Dexter, and C. Baraloto. 2011. Phylogenetic density dependence and environmental filtering predict seedling mortality in a tropical forest. Ecology Letters 15:34-41.

Paine, R. T. 1969. A note on trophic complexity and community stability. American Naturalist 103:91-93.

Pandolfi, J. M., and J. B. C. Jackson. 2001. Community structure of Pleistocene coral reefs of Curaçao, Netherlands Antilles. Ecological Monographs 71:49-67.

Pandolfi, J. M., and J. B. C. Jackson. 2006. Ecological persistence interrupted in Caribbean coral reefs. Ecology Letters 9:818-826.

Petermann, J. S., A. J. F. Fergus, L. A. Turnbull, and B. Schmid. 2008. Janzen-Connell effects are widespread and strong enough to maintain diversity in grasslands. Ecology 89:2399-2406.

Porter, J. W. 1972. Predation by Acanthaster and its effects on coral species diversity. American Naturalist 106:487-492.

$\mathrm{R}$ Development Core Team. 2007. R version 2.6.0. www. R-project.org

Reshef, L., O. Koren, Y. Loya, I. Zilber-Rosenberg, and E. Rosenberg. 2006. The coral probiotic hypothesis. Environmental Microbiology 8:2068-2073.

Ritchie, K. B. 2006. Regulation of microbial populations by coral surface mucus and mucus-associated bacteria. Marine Ecology Progress Series 322:1-14.

Ritson-Williams, R., S. N. Arnold, N. D. Fogarty, R. S. Steneck, M. J. A. Vermeij, and V. J. Paul. 2009. New perspectives on ecological mechanisms affecting coral recruitment on reefs. Smithsonian Contributions to the Marine Sciences 38:437-457.

Rohwer, F., V. Seguritan, F. Azam, and N. Knowlton. 2002. Diversity and distribution of coral-associated bacteria. Marine Ecology Progress Series 243:1-10.

Rohwer, F., and M. Youle. 2010. Coral reefs in the microbial seas. Plaid Press, Basalt, Colorado, USA.

Rosenberg, E., C. A. Kellogg, and F. Rohwer. 2007. Coral microbiology. Oceanography 20:146-154.

Rypien, K. L., J. R. Ward, and F. Azam. 2010. Antagonistic interactions among coral-associated bacteria. Environmental Microbiology 12:28-39.

Sandin, S. A., and S. W. Pacala. 2005. Fish aggregation results in inversely density-dependent predation on continuous coral reefs. Ecology 86:1520-1530.

Sharp, K. H., K. B. Ritchie, P. J. Schupp, R. Ritson-Williams, and V. J. Paul. 2010. Bacterial acquisition in juveniles of several broadcast spawning coral species. PLoS One 5:e10898.

Tremblay, P., M. G. Weinbauera, C. Rottiera, Y. Guérardela, C. Nozaisa, and C. Ferrier-Pagès. 2011. Mucus composition and bacterial communities associated with the tissue and skeleton of three scleractinian corals maintained under culture conditions. Journal of the Marine Biological Association of the United Kingdom 91:649-657.

Van Duyl, F. C. 1985. Atlas of the living reefs of Curaçao and Bonaire (Netherlands Antilles). Publications of the Foundation Natuurwetenschappelijke Studiekring voor Suriname en de Nederlandse Antillen 117:1-38.

Van Moorsel, G. W. N. M. 1983. Reproductive strategies in two closely related stony corals (Agaricia, Scleractinia). Marine Ecology Progress Series 13:273-283.

Vermeij, M. J. A. 2005. Substrate composition and adult distribution determine recruitment patterns in a Caribbean brooding coral. Marine Ecology Progress Series 295:123-133.

Vermeij, M. J. A., and R. P. M. Bak. 2003. Species-specific population structure of closely related coral morphospecies along a depth gradient (5-60 M) over a Caribbean reef slope. Bulletin of Marine Science 73:725-744.

Vermeij, M. J. A., N. D. Fogarty, and M. W. Miller. 2006. Pelagic conditions affect larval behavior, survival, and settlement patterns in the Caribbean coral Montastraea faveolata. Marine Ecology Progress Series 310:119-128. 
Vermeij, M. J. A., and S. A. Sandin. 2008. Density-dependent settlement and mortality structure the earliest life phases of a coral population. Ecology 89:1994-2004.

Vermeij, M. J. A., S. A. Sandin, and J. F. Samhouri. 2007. Local habitat distribution determines the relative frequency and interbreeding potential for two Caribbean coral morphospecies. Evolutionary Ecology 21:27-47.

Vermeij, M. J. A., J. E. Smith, C. M. Smith, R. Vega Thurber, and S. A. Sandin. 2009. Survival and settlement success of coral planulae: independent and synergistic effects of macroalgae and microbes. Oecologia 159:325-336.

Veron, J. E. N. 1995. Corals in space and time: the biogeography and evolution of the Scleractinia. Cornell University Press, Ithaca, New York, USA.
Wegley, L., R. Edwards, B. Rodriguez-Brito, H. Liu, and F. Rohwer. 2007. Metagenomic analysis of the microbial community associated with the coral Porites astreoides. Environmental Microbiology 9:2707-2719.

Wild, C., M. Huettel, A. Klueter, S. G. Kremb, M. Y. M. Rasheed, and B. B. Jørgensen. 2004. Coral mucus functions as an energy carrier and particle trap in the reef ecosystem. Nature 428:66-70.

Williamson, C. H. K. 1996. Vortex dynamics in the cylinder wake. Annual Review of Fluid Mechanics 28:477-539.

Wills, C., et al. 2006. Nonrandom processes maintain diversity in tropical forests. Science 311:527-531.

\section{Supplemental Material}

\section{Appendix}

Parameter estimations and maximum-likelihood values for experiments depicted in Figs. 2-7 (Ecological Archives E094-013-A1). 